\title{
HISTOLOGICAL, HISTOCHEMICAL AND IMMUNOHISTOCHEMICAL STUDIES ON THE PARAVENTRICULAR AND SUPRAOPTIC NUCLEI OF THE HYPOTHALAMUS IN THE ADULT NEW ZEALAND RABBITS
}

\author{
SOLIMAN, SH.M.M.; MAZHER, KH.M.; TAGHREED, M.N.; MOAWAD, U.K. and \\ HASSAN, R.M.
}

Department of Cytology and Histology, Faculty of Veterinary Medicine, Beni-Suef University

Email: dr.usamakm2013@yahoo.com

Assiut University web-site: www.aun.edu.eg

\section{ABSTRACT}

Received at: $30 / 9 / 2015$

Accepted: 31/10/2015
The present investigation aims to give a detailed histomorphological feature of the anterior group of hypothalamus of adult New Zealand rabbits in both sexes. Specimens were prepared to be examined microscopically by using light and transmission electron microscope. The obtained results revealed that, the anterior group of the hypothalamus composed of paraventricular (PVN) and supraoptic nuclei (SON). The paraventricular nucleus was located on either sides of the $3^{\text {rd }}$ ventricle. It consisted of different-shaped neurons which appeared in the form of clusters and irregular groups intermingled with nerve fibers associated with neuroglia cells and permeated by blood capillaries. Ultrastructurally, the neurons appeared polyhedral in shape contained large eccentric euchromatic nucleus and electron lucent cytoplasm contained many mitochondria, rER, Golgi apparatus, numerous ribosomes and some secretory granules. On the other hand, the supraoptic nucleus was located dorsolateral to the optic chiasma and consisted of two portions; thin medial and thick lateral one. The neurons of the thin medial part appeared pyramidal in shape with vesicular oval eccentric nuclei and lightly stained cytoplasm, while that of the thick lateral one showed irregular groups or rows of oval and pyriform shaped cells contained vesicular rounded eccentric nuclei. Ultrastructurally, the neurons of the thick lateral part of SON appeared pyriform in shape with spherical eccentric euchromatic nucleus in electron lucent cytoplasm showed intensive network of rER, many mitochondria, Golgi apparatus, numerous free ribosomes and few secretory granules. The cytoplasmic granules of the PVN and SON neurons gave positive reaction with all nonspecific and specific stains used. Also, they gave positive immunoreactions when subjected to Anti-CGA and Anti-NSE antibodies. There were no microscopic structural differences correlated to neither sex nor age of studied animals.

Key words: Immunohistochemical, Paraventricular, Supraoptic nuclei, Hypothalamus, Rabbits.

\section{INTRODUCTION}

Rabbits act as a significant source of meat in different countries; this supports the idea that the rabbit will be more widely used for specific biotechnology projects. It is a standard laboratory animal (good experimental model) in biomedical research and transgenic rabbits are used as animal models for a variety of human diseases both genetic and acquired, classical experimental use of rabbits includes antibody production, development of new surgical techniques, physiology and toxicity studies for the testing of new drugs. The scientific community uses rabbits as experimental animals or as a tool to produce biotechnology products and others involved in breeding (BÕsze and Houdebine, 2006). Graur et al. (1996) said that the rabbit is phylogenetically closer to primates than rodents and is large enough to permit non-lethal monitoring of physiological changes. The great similarity to the anatomy and the histology of human, appropriate size, easy-handling and care make the rabbit an attractive animal for the use as experimental and research model (De la Portilla et al., 2011). 
The anterior group of the hypothalamic nuclei composed of paraventricular (PV) and supraoptic (SO) nuclei. The hypothalamic PVN and SON complex was an excellent model system for the study of the control of neuroendocrine cells (NECs), from receptor activation to mRNA transcription in human (Stafford and Lightman, 1988). This system (PVN) composed of two major divisions; the parvocellular system of the PVN which extremely complex and has many neuroendocrine, autonomic and behavioral roles. The other one is the magnocellular system which composed of two sets of neurons synthesizing either vasopressin or oxytocin mingled within both the SON and PVN, and carried by axoplasmic transport to the neurohypophysis, from where, it was released into the venous circulation in response to appropriate stimuli (Leng et al., 1999).

The SON neurons have a double function: they were hormone-secreting cells and act as neuronal elements (Saphier and Feldman, 1985). By using immunohistochemical staining, Shi, et al. (2012) decided that, the vasopressin and oxytocin hormones were mainly synthesized in the magnocellular cells of the hypothalamic supraoptic and paraventricular nuclei whose axons project to the posterior pituitary and their neurons have special patterns in location and distribution within the two nuclei.

The aim of the present investigation is to visualized the histomorphological features of both paraventricular and supraoptic nuclei of the hypothalamus with the aid of light and transmission electron microscope in addition to histochemical and immunohistochemical reactions to illustrate their functional activity.

\section{MATERIALS and METHODS}

\section{(I) For Light microscopic examination:}

A total number of twenty-six apparently healthy mature New Zealand rabbits aging from 8 -12 month were used in the present investigation collected from Beni-Suef and El-Wasta rabbits breeding Farms. Immediately after slaughtering, the dorsal part of the skull was removed and the whole head including the brain were immersed in the following fixatives; $30 \%$ formalin and Bouin's fluid. The brain was allowed to harden for several hours in the fixative and then was carefully removed from the skull to minimize damage of the brain tissue.

The brain samples were crossly cut at the point of thalamus and hypothalamus. The dissected specimens were examined grossly for any pathological lesions and only apparently normal ones were taken then immediately return to the fixatives. All samples were processed to prepare serial sections of about 4-6 $\mu \mathrm{m}$ thick then stained with the following stains: Harris Hematoxylin and Eosin (Harris, 1900) and Toluidine blue stain for semi-thin sections (Richardson et al., 1960) as general stains for general histological examination; Grimelius silver impregnation technique (Grimelius, 1968) and Lead Hematoxylin stain (Solcia et al., 1968) for detection of all endocrine granules as non- specific stains for neurosecretory granules; Gomori's aldehyde fuchsin stain "AF" (Bargmann, 1949), Gomori's chrome alum hamatoxylin stain "CAH" (Gomori, 1941) and Performic acid alcian blue stain "PA-AB" (Adams and Sloper, 1955) as specific stains for detection of neuroendocrine granules. Moreover, Immunohistochemical detection of Chromogranin A using Anti-CGA clone DAK-A3 by application of PAP technique using monoclonal mouse anti-human antibody on the brain (Lassman et al., 1986) and Neuron Specific Enolase using Anti-NSE clone BBS/NC/VI-H14 by application of PAP technique using monoclonal mouse anti-human antibody (Schmechel et al., 1978).

The above mentioned fixatives and stains were applied as outlined by Bancroft \& Stevens (1996) and Bancroft \& Gamble (2008).

\section{(II) For Transmission Electron microscopic Examination:}

Four samples were collected from paraventricular and supraoptic nuclei; two at 8 months and two at one year of age; one sample from each nucleus at each age. The taken samples from the two nuclei were determined as shown by Shek et al. (1986) in the atlas of the rabbit brain and spinal cord. The collected specimens were cut into very small pieces of about 1$3 \mathrm{~mm}$ thick and prefixed in $3 \%$ gluteraldhyde in phosphate buffer solution ( $\mathrm{PH}$ 7.4) at room temperature for $4 \mathrm{hrs}$, then washed three times in the same buffer and kept in it overnight at $4^{\circ} \mathrm{C}$ (Hayat, 1986) before they were post-fixed in $1 \%$ osmium tetroxide in phosphate buffer for $2 \mathrm{hrs}$ at $4^{\circ} \mathrm{C}$, then rinsed three times in distilled water, dehydrated in ethanol, cleared in propylene oxide and then embedded in Epon. Semi thin sections of about 0.5$1 \mu \mathrm{m}$ thick were obtained and stained with toluidine blue then examined by the light microscope to determine the selected area (Richardson et al., 1960). Ultra-thin sections $50-60 \mathrm{~nm}$ thick of the selected area were obtained and contrasted with $5 \%$ uranyle acetate dissolved in $70 \%$ ethanol followed by lead citrate stain (Reynolds, 1963), examined in the electron microscopy unit in Faculty of Agriculture, Cairo University, by using of transmission electron microscope JEOL (JEM-1400 TEM) at the candidate magnification. 


\section{RESULTS}

Anatomically, the hypothalamus of the New Zealand rabbit represented the most ventral part of the diencephalon. It is situated on either sides of the third ventricle, with the hypothalamic sulcus delineating its dorsal border. The ventral aspect of the hypothalamus exposed on the base of the brain. It extended from the rostral limit of the optic chiasma to the caudal limit of the mamillary bodies. In the present study, two hypothalamic nuclei of the anterior group were studied; the Paraventricular (PV) and the Supraoptic (SO) nuclei.

\section{1) Paraventricular nucleus:}

\section{Light microscopical structure:}

Generally, the PVN observed as an inverted pyramidal-shaped organization beside the $3^{\text {rd }}$ ventricle on its two lateral sides (Fig. 1). It consisted of neurons of different shapes showing irregular distribution as clusters and irregular groups. The neurons were intermingled with nerve fibers and glia cells (Fig. 2). These neurons appeared with different shapes (pyriform, oval, polyhedral and star-shaped) cells containing spherical eccentric vesicular nuclei with prominent nucleoli. The cytoplasm appeared homogenous, finely granular and basophilic. The glia cells appeared smaller in size, irregular in outline housing less basophilic cytoplasm and deeply-stained nuclei (Fig. 3).

With Grimelius silver impregnation, the secretory multipolar neurons of paraventricular nucleus appeared with intense dark brownish argyrophilic granules distributed all over the neuroplasm and neuroplasmic processes (Fig. 4). By using lead hematoxylin stain, their neuroplasmic endocrine granules appeared stained with different degree of positive blue-black colour (Fig. 5).

The cytoplasmic neuroendocrine granules of their neurons stained with purple violet colour by using Gomori's aldehyde fuchsin stain. The reaction appeared with different degrees from weak, moderate to strong reactions (Fig. 6).

In a cross section stained with Gomori's chrome alum hematoxylin stain, the PVN neurons showed deep staining of the neurosecretory granules. They appeared dark blackish blue in colour. The granules concentrated mainly in one pole of the cell (Fig. 7). With performic acid alcian blue stain, the neuroendocrine cytoplasmic granules of the PVN neurons gave strong positive reaction. They appeared with blue colour concentrated in one cytoplasmic pole. Also, the nerve fibers appeared with positive granules (Fig. 8).
The PVN magnocellularne urons were subjected to Anti-CGA antibody using PAP technique and gave positive reaction. Their cytoplasmic granules stained with brown colour. They appeared small, accumulated at one cytoplasmic pole and showed moderate reaction (Fig. 9). The PAP technique using Anti-NSE antibody application on the PVN neurons gave astrong reaction indicated by dark brown colour. Their positive cytoplasmic granules were small and filled the whole cytoplasm (Fig. 10).

\section{Electron microscopical structure:}

The neuron appeared large polyhedral in shape, contained electron lucent cytoplasm and large eccentric euchromatic nucleus with prominent nucleolus. Protoplasmic astrocytewas noticed associated with the PVN neuron, it appeared small oval cell with cytoplasmic processes and electron dense cytoplasm housing euchromatic oval central nucleus (Fig. 11). The cytoplasmic organelles of the neurons were represented by many mitochondria distributed all over the cytoplasm, many granular cisternae of rER, Golgi apparatus, numerous ribosomes and some electron dense secretory granules (Fig. 12).

\section{2) Supraoptic nucleus:}

\section{Light microscopical structure:}

Anatomically, the hypothalamic Supraoptic Nucleus (SON) of the adult New Zealand rabbit was located dorsolateral to the optic chiasma. It appeared to be formed of two portions; the first one was the thin medial portion which found only dorsal to the optic chiasma toward the center of the brain. While, the second portion was thick lateral portion that surrounding the optic chiasma laterally (Fig. 13).

The neurons of the thin medial part of the SON were extended in the form of compact aggregates dorsal to the optic chiasma. These neurons appeared large oval or pyramidal shaped cells with vesicular oval eccentric nuclei and lightly stained cytoplasm intermingled with some apoptotic cells with condensed flattened nuclei and deeply stained cytoplasm (Fig. 14). They supported by glia cells. On the other hand, the neurons of the lateral part arranged in irregular groups or rows permeated by continuous blood capillaries. They appeared oval or pyriform in shape contained vesicular round eccentric nuclei with clear nucleoli and basophilic cytoplasm (Fig. 15). Groups of nerve fibers were present in between the neurons. Also, the neuroglia cells in close association to the neurons were present.

In a cross section through the two portions of SON, stained with Grimelius silver impregnation, the neurons showed intense brownish black argyrophilic granules distributed all over the cytoplasm and 
cytoplasmic processes (Fig. 16). By using lead Hematoxylin stain, the cytoplasmic granules reacted strongly giving blue-black colour (Fig. 17).

The cytoplasmic neuroendocrine granules appeared with purple violet colour when subjected to Gomori's aldehyde fuchsin stain. The reaction appeared with different degrees weak, moderate and strong reactions. The pyramidal cells of the medial portion appeared with moderate reaction in their cytoplasmic neuroendocrine granules. While the pyriform neurons of the lateral portion having moderate reaction in some cells and strong reaction in other cells. The granules concentrated in one cytoplasmic pole (Figs. 18).

In a section stained with Gomori's chrome alum Hematoxylin stain, the SON neurons showed deeply stained neurosecretory granules. They appeared dark blackish blue in colour. The granules concentrated mainly in one pole of the cell (Fig. 19).

The neuroendocrine cytoplasmic granules of neurons of the two portions gave moderate to strong reaction with performic acid alcian blue stain. They appeared with blue colour concentrated in one cytoplasmic pole (Fig. 20).

The SON neurons were subjected to Anti-CGA antibody using PAP technique and gave weak to moderate reaction. Their cytoplasmic granules stained with brown colour. They appeared small and filled the whole cytoplasm and cytoplasmic processes (Fig. 21). The blood capillary contained positive granules. The application of PAP technique using Anti-NSE antibody resulted in moderate to strong reaction of brown colour in the SON neurons. The positive cytoplasmic granules appeared small in size and filled the whole cytoplasm (Fig. 22).

\section{Electron microscopical structure:}

The SON neurons appeared pyriform in shape with electron lucent cytoplasm and spherical eccentric euchromatic nucleus with prominent nucleolus. The neurons were in close association with the neuroglia cells. The protoplasmic astrocyte appeared smaller in size with electron dense cytoplasm and oval more heterochromatic nucleus (Fig. 23).

The cytoplasm of the neuron showed extensive network of granular endoplasmic reticulum (rER) with dilated cisternae, many mitochondria, Golgi apparatus, numerous free ribosomes and some electron dense secretory granules (Fig. 24).

There were no microscopic structural differences correlated to neither sex nor age of studied animals.

\section{LIST OF FIGURES}

Fig. 1: A photomicrograph of the hypothalamus of the adult New Zealand rabbit showing an inverted pyramidal shaped organization of PVN (P) around the $3^{\text {rd }}$ ventricle (V). H\&E stain, X100.

Fig. 2: A photomicrograph of the hypothalamus of the adult New Zealand rabbit showing irregular distribution of PVN-neurosecretory cells (arrows) that arranged in the form of clusters and irregular groups supported by glia cells (arrowheads). H\&E stain, X 400 .

Fig. 3: A cross section through the PVN of the adult New Zealand rabbit showing multipolar neurons (arrows) with vesicular nuclei, neuroglia cells (arrowheads) associated with the neurons. Toluidine blue stain, X1000.

Fig. 4: A section through PVN neurons of the adult New Zealand rabbit showing different multipolar neurons (arrows) with argyrophilic granules of dark brownish colour distributed all over the cytoplasm. Note, the nerve fibers contain positive granules (arrowheads). Grimelius silver impregnation stain, $\mathrm{X} 1000$.

Fig. 5: A photomicrograph of PVN neurons in adult New Zealand rabbit showing positive blue-black reaction of different degrees in the cytoplasmic granules (arrows). Lead hematoxylin stain, X1000.

Fig. 6: A cross section through the PVN of the adult New Zealand rabbit showing weak (arrowheads), moderate (arrows) and strong (double arrows) reaction (purple violet colour) in the neurons. Gomori's aldehyde fuchsin stain, X1000.

Fig. 7: A section through the PVN of the adult New Zealand rabbit showing deeply stained pyramidal neurons (arrows) with dark blackish blue colour. Gomori's chrome alum hematoxylin stain, X1000.

Fig. 8: A section through the PVN of the adult New Zealand rabbit showing moderate to strong reaction (intense blue colour) in the neuroplasm of different neurons (arrows). Performic acid alcian blue stain, $\mathrm{X} 1000$.

Fig. 9: A photomicrograph of the PVN of the adult New Zealand rabbit showing moderate reaction (brown colour) in cytoplasmic granules of the neurons (arrows). Immunoreaction with Anti-CGA antibody, X1000. 
Fig. 10: A cross section through the PVN of the adult New Zealand rabbit showing their neurons with strong reaction (dark brown colour) in their cytoplasmic granules (arrows). Immunoreaction with Anti-NSE antibody, X1000.

Fig. 11: An electron micrograph of the PVN of the adult New Zealand rabbit showing polyhedral neurons (arrows). Protoplasmic astrocyte (arrowhead) appeared small and oval with euchromatic central nucleus $(\mathrm{N})$ and electron dense cytoplasm. Uranyle acetate and lead citrate stain, X3000.

Fig. 12: A higher magnification of figure (11) showing the PVN neuron with euchromatic nucleus $(\mathrm{N})$, many mitochondria (M), many rER cisternae $(\mathrm{R})$, Golgi apparatus (G), numerous free ribosomes (F) and some electron dense secretory granules (arrows). Uranyle acetate and lead citrate stain, X 12000 .

Fig. 13: A cross section through the hypothalamus of the adult New Zealand rabbit showing the SON formed of a thin medial part (M) and a thick lateral part (L). Note, the optic chiasma (O). H\&E stain, $\mathrm{X} 100$.

Fig. 14: A higher magnification of figure (13), showing the medial part of the SON contains large oval or pyramidal neurons (arrows) with vesicular nuclei and lightly stained cytoplasm intermingled with some apoptotic cells with condensed nuclei and deeply stained cytoplasm (arrowheads). Note, the optic chiasma (O). H\&E stain, X1000.

Fig. 15: A higher magnification of figure (13), showing large oval and pyriform neurons (arrows) with vesicular round nuclei and basophilic cytoplasm in the lateral part of SON. The neurons supported by glia cells (arrowheads). Note, the optic chiasma (O) and the blood capillary (C). H\&E stain, X1000.

Fig. 16: A section through the lateral portion of the SON of the adult New-Zealand rabbit showing neurons with strong argyrophilic granules of brownish black colour (arrows). Grimelius silver impregnation stain, X1000.

Fig. 17: A photomicrograph of the SON of the adult New Zealand rabbit showing the neurons of the lateral portion with strong positive (blue-black) reaction (arrows). Lead hematoxylin stain, X1000.

Fig. 18: A higher magnification of the lateral portion of the SON in the adult New Zealand rabbit showing moderate purple violet reaction in some neurons (arrowheads) and strong reaction (arrows) in the others. Gomori's Aldehyde fuchsin stain, X1000.

Fig. 19: A section through the SON of the adult New Zealand rabbit showing neurons of the lateral portion having positive (dark blackish blue colour) reaction (arrows). Gomori's chrome alum Hematoxylin stain, $\mathrm{X} 1000$.

Fig. 20: A photomicrograph of SON of the adult New Zealand rabbit showing neurons of the lateral portion having moderate to strong blue colouration in their cytoplasmic granules (arrows). Performic acid alcian blue stain, X1000.

Fig. 21: A section through the SON of the adult New Zealand rabbit showing weak to moderate reaction (brown colour) in the cytoplasmic granules of neurons (arrows). Note, the optic chiasma $(\mathrm{O})$ and the blood capillary (C).PAP technique using Anti-CGA antibody, X1000.

Fig. 22: A cross section through the SON of the adult New Zealand rabbit showing the cytoplasmic granules of neurons with moderate to strong reaction of brown colour (arrows). Note, the optic chiasma (O). PAP technique using Anti-NSE antibody, $\mathrm{X} 1000$.

Fig. 23: An electron micrograph of the lateral portion of the SON of the adult New Zealand rabbit showing pyriform neuron (arrow) containing large spherical eccentric euchromatic nucleus $(\mathrm{N})$ with clear nucleoli, electron lucent cytoplasm and axon (A). Note, the protoplasmic astrocyte cell (arrowhead). Uranyle acetate and lead citrate stain, X3000.

Fig. 24: A higher magnification in the neuron of the lateral portion showing euchromatic nucleus $(\mathrm{N})$, many mitochondria $(\mathrm{M})$, extensive dilated cisternae of rER (R), Golgi apparatus (G), numerous free ribosomes $(\mathrm{F})$, and few electron dense secretory granules (arrows). Uranyle acetate and lead citrate stain, X12000. 

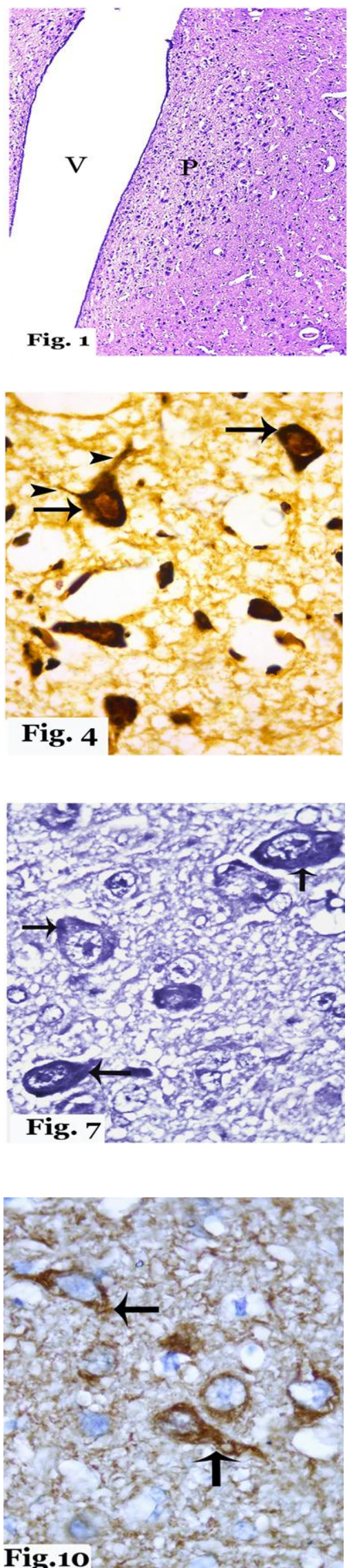
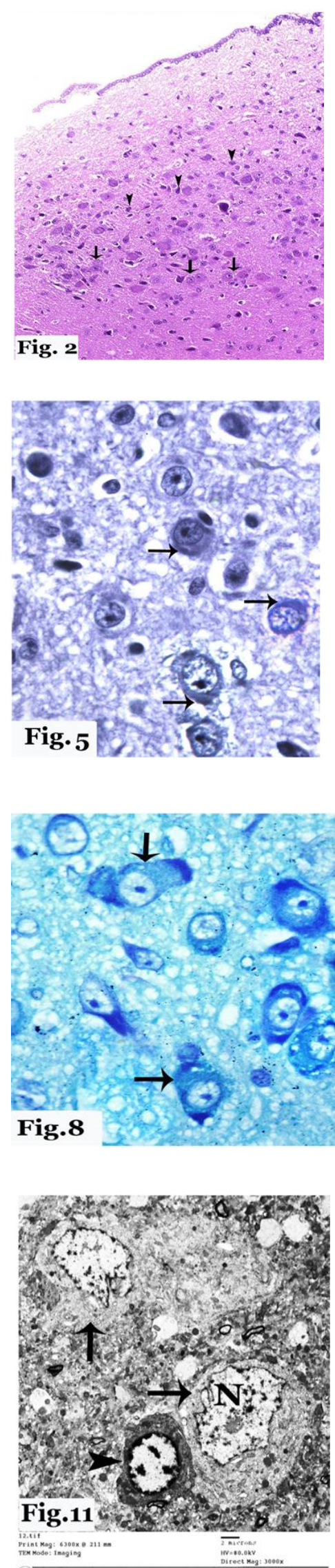
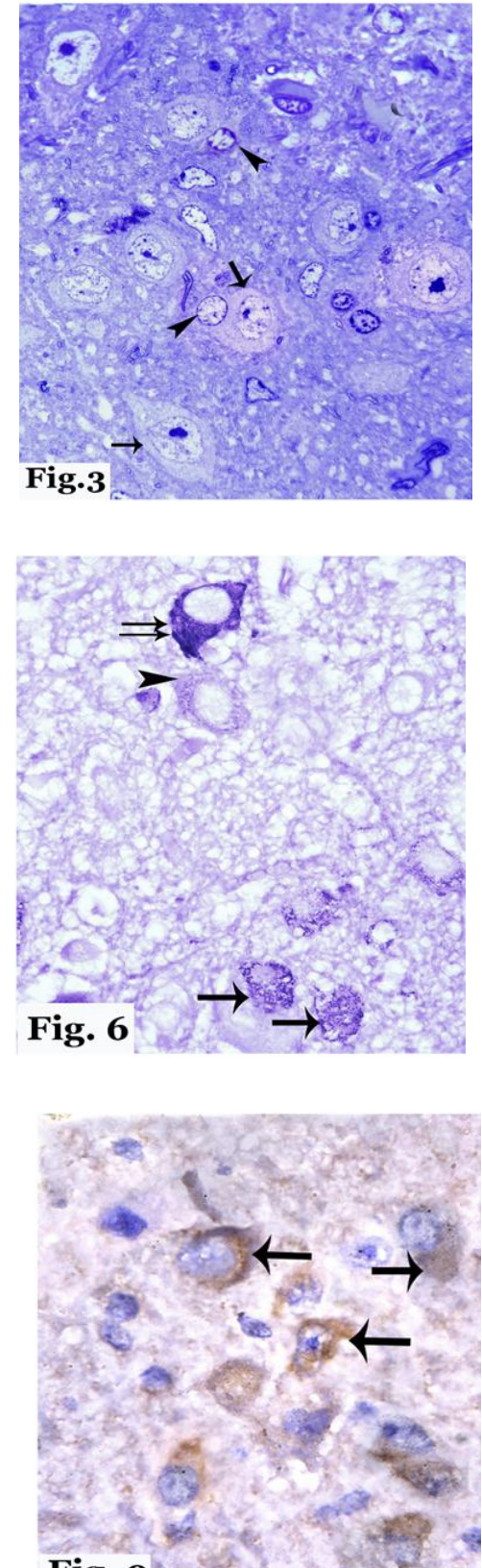

Fig. 9

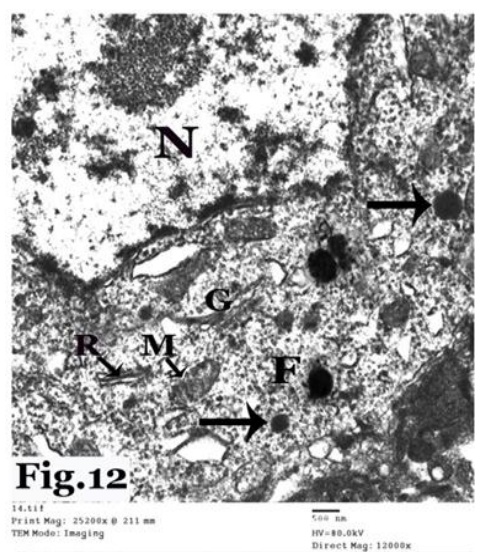




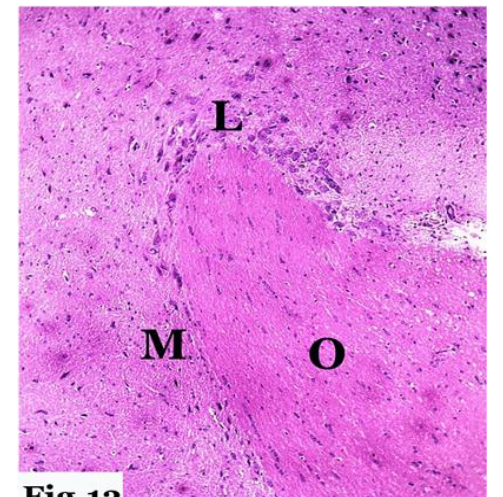

Fig.13
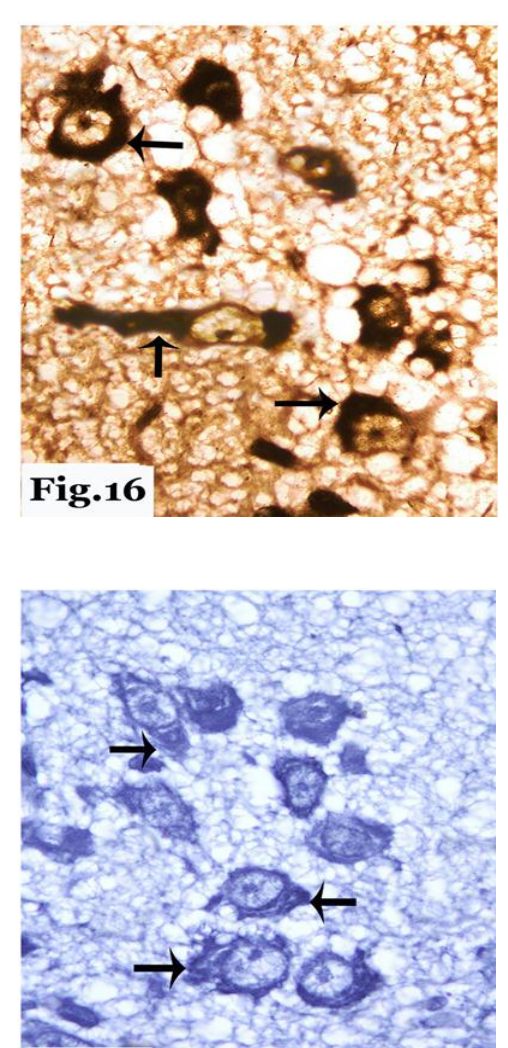

Fig.19 $x$, तो

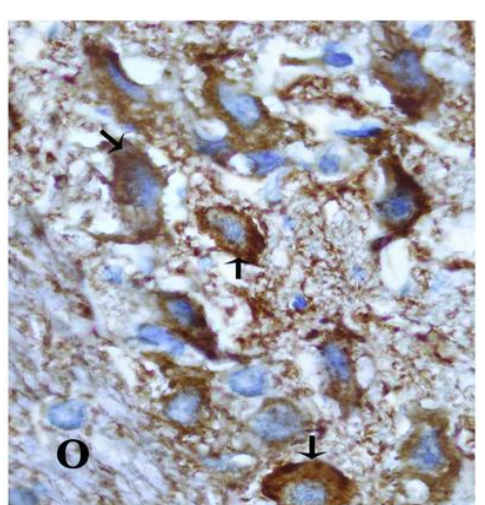

Fig.22 2020 की
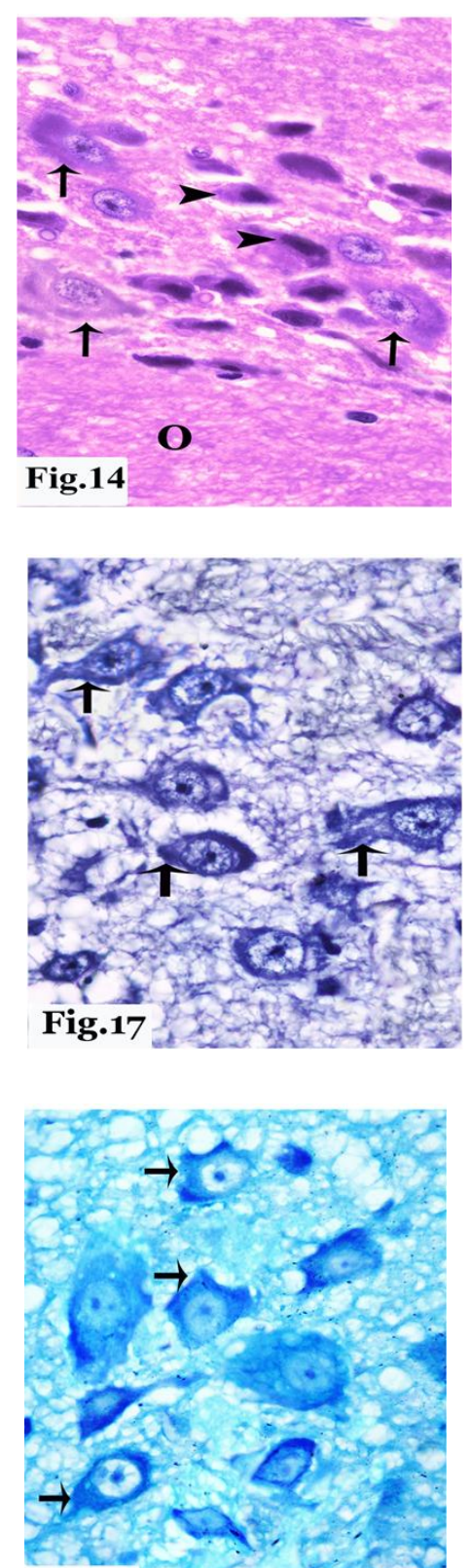

Fig.20 - 0070

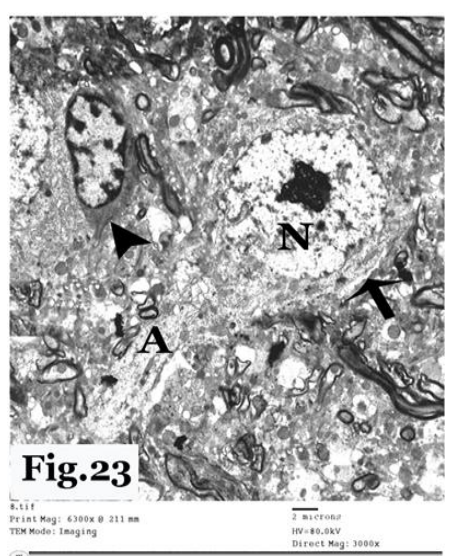

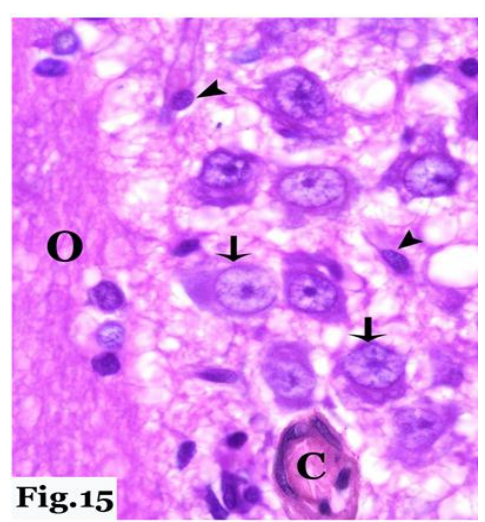
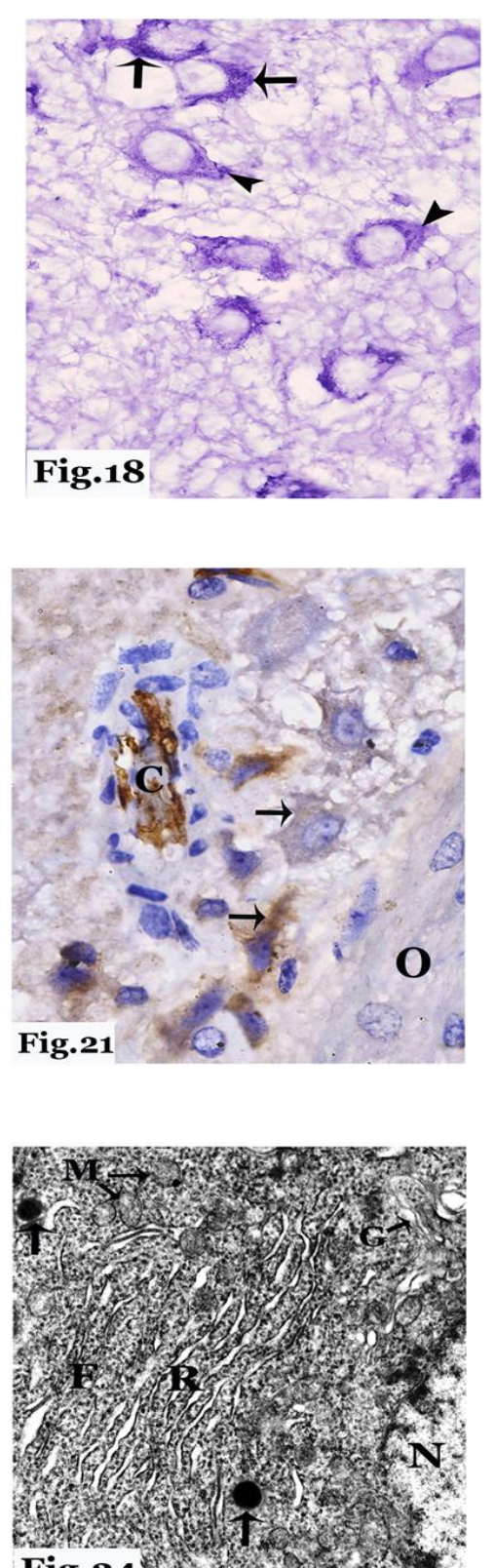

Fig.24 6 .

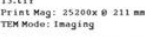

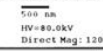




\section{DISCUSSION}

Hypothalamus includes three groups of neurons; anterior, middle and posterior ones that the name of the neuron groups was given according to the position of each. The anterior group was composed of supraoptic and paraventricular nuclei (Cotea et al., 2007).

\section{1- The Paraventricular Nucleus (PVN):}

It has been found that, the hypothalamic PVN of the adult New Zealand rabbit could be characterized as an inverted pyramidal-shaped organization located on the two lateral sides of the $3^{\text {rd }}$ ventricle. Their neurons showed irregular distribution as clusters and irregular groups permeated with blood capillaries. Similar organization was showed in white rat (FlamentDurand and Dustin, 1972). Nearly similar results regarding the site of the nucleus but differ in their neurons distribution recorded in mouse (Barry, 1975), cat (Bisset et al., 1970) and dog (Leontovich, 1970). In albino rat, Hyyppä (1969); in human, Swaab and fliers (1985) and Zaborszky et al. (2008) stated that the PVN located along the $3^{\text {rd }}$ ventricle and contained groups of large, darkly stained neurons.

Both the paraventricular and supraoptic nuclei of adult New Zealand rabbit were permeated by many blood capillaries and supported by neuroglia cells. In this respect, Ambach and Palkovits (1979) stated that the PVN and SON were the most highly vascularized parts of the hypothalamus. Leveque (1983) in adult white ratadded that the dense vascularity may be interpreted as an indication of high metabolic activity.

There was a close association between the neurons and neuroglia cells in the PVN and SON. This augmented by Duan et al. (2004) who recorded that the magnocellular neurons connected with the astrocytes by a gap junction and there was a rapid adaptive signal structure between neurons and astrocytes in response to stimulation.

In adult New Zealand rabbit under investigation, the PVN neurons appeared as large polyhedral cell contained large eccentric euchromatic nucleus with prominent electron lucent nucleolus and electron lucent cytoplasm showed many distributed mitochondria, multiple cisternae of rER, numerous ribosomes and few electron dense secretory granules. Similar results were recorded in rat (Kalimo, 1975 and Gregory et al., 1980) who observed a single neuronal type. While, in adult dormouse Machfnsantamaria (1978) described 3 types of PVN neurons; light, dark neurons and intermediate type neurons which showed some of the features of both.

\section{2- The Supraoptic Nucleus (SON):}

The present study showed that, the hypothalamic SON of the adult New-Zealand rabbit was located dorsolateral to the optic chiasma and formed of two portions; a thin medial part found only dorsal to the optic chiasma extended in form of compact aggregates and a thick lateral part surrounding the optic chiasma laterally and their neurons arranged in irregular groups or rows. Similar results were recorded in albino rat (Freund-Mercier et al., 1994) and cat (Bisset et al., 1970) as well as in human (Fliers et al., 1985).

Our observation revealed that, the neurons of the thin medial part of the SON appeared large oval or pyramidal shaped with vesicular oval eccentric nuclei and lightly stained cytoplasm intermingled with some apoptotic cells containing condensed flattened nuclei and deeply stained cytoplasm. On the other hand, the neurons of the lateral part appeared oval or pyriform in shape contained vesicular round eccentric nuclei with clear nucleoli and basophilic cytoplasm. Nearly similar results were recorded in rabbit (Felten and Cashner, 1979), rats (Bazhanova et al., 1998), mouse (Barry, 1975) and guinea pig (Sofroniew et al., 1979). Different results were obtained in cow (Cotea et al., 2007).

Ultrastructurally, the SON neurons showed signs of active protein synthesis processes; extensive network of granular endoplasmic reticulum (rER) with dilated cisternae, many mitochondria, Golgi apparatus and numerous free ribosomes. This result augmented by results of Bazhanova et al. (1998) in waster rat. Generally, the SON neurons have abundant Nissl substances and neurosecretory granulesas revealed by Scharrer and Scharrer (1954).

The PVN and SON neurons under investigation contained few secretory granules. This result was disagreed with that discussed by some previously mentioned authors. In this respect, Kalimo (1975) in rat and Bisset et al. (1970) in cat explained that the number of neurosecretory granules varies from cell to cell. The decrease of their number in stimulated neurons considered to corroborate the proposed existence of an extragranular phase axoplasmic transport mechanism in PVN and SON neurons through the hypothalamo-hypophysial tract via the nerve fibers to the pars nervosa and had been discharged during stimulation.

It has been found that, the two nuclei in our study gave positive reaction appeared as brownish black coloured granules after treatment with Grimelius technique. This intense positive reaction indicates that these cells contained argyrophilic endocrine granules. The argyrophilic reactions caused by CGA as recorded by Lundqvist et al. (1990). This reaction discussed by Bancroft and Gamble (2008) who explained that the argyrophil stain after addition of reducing agent that reduce the bounded silver salts from $\mathrm{Ag}+1$ to metallic silver $\mathrm{Ag}^{\circ}$ which was 
deposited and so the cellular organelles make absorption to the silver salts from the basic solution and give the positive colour. Consequently, Cetin (1992) in guinea pig, cattle, pig and man stated that the argyrophilic stain has recently been attributed to chromogranin A, an acidic glycoprotein that is present in many endocrine cells.

The neurons of the two nuclei reacted positively with Lead haematoxylin, this reaction explained by Solcia et al. (1968) and Bancroft and Gamble (2008) as the carboxyl groups released from the polypeptide secretion inside any endocrine cells reacted with and changed the colour of basic dyes as lead haematoxylin. Also, the use of acid hydrolysis prior to the staining gave a better result due to aid in the elaboration to the carboxyl groups to be free and give their reaction with the stain.

Regarding the specific stains, we applied some classic histochemical methods which could detect and identify the neuroendocrine cells in the PVN and $\mathrm{SON}$ in addition to some IHC reactions which react and recognize general biomarkers specific to neuroendocrine cells. All techniques served for identifying these cells, proving their neural origin and regulatory peptides in the form of neurosecretory granules. This work was supported by Scharrer (1967). These reactions were depending upon identification of certain substances (amino acids) that reacted with the active radical of the stain or by demonstration of products resulting from either oxidation orreduction of the disulphide bonds present in neurosecretory materials (Watkins, 1975).

According to Scharrer and Scharrer (1954) and Sloper (1989), the aldehyde fuchsin stain was a technique used for identification of neurosecretory materials in hypothalamus and hypothalamo-hypophysial tract. This dye has a special affinity for highly reducing groups in the sulfated amino acids. Sloper (1989) explained that the neuroendocrine cells rich in cysteine amino acids contain a highly reducing essential groups (disulphide"-SS"). The SS- group reduced to sulphydryle (-SH) groups which react with the active radical of this stain and produce the positive colour.

Positive reaction of both nuclei under investigation by using chrome alum haematoxylin stain was discussed by Pearse (1977) who stated that this technique used for identification of NSM in hypothalamus and hypothalamo-hypophysial tract as this dye has a special affinity for the sulphydryle (-SH) groups of the special protein present in the neurosecretory materials.

According to Bancroft and Stevens (1996), the neurosecretory materials inside the axons of neurohypophysis were stained well with the performic acid-alcian blue technique of Adams and Sloper (1955). With this technique, the neuroendocrine cytoplasmic granules of the PVN neurons of adult New Zealand rabbit gave strong positive reaction of blue colour concentrated in one cytoplasmic pole. Also, the nerve fibers appeared with positive granules. Similar results were observed by Adams and Sloper (1955) in human who revealed that, the positive $\mathrm{PA}-\mathrm{AB}$ blue material was aggregated in the cell bodies of the PVN neurons and spread down their axons. This method demonstrating the presence of disulphide (-SS) groups which were essential for the synthesis of the neurosecretory materials in the neurosecretory cells according to Rao et al. (1988) that indicating the presence of cystine and cysteine rich NSM and the intensity of the blue colour depended on the amount of disulphide groups. This reaction explained by Adams and Sloper (1956) who recorded that the cysteine or cystine amino acids in the tissue oxidized with very strong oxidant as performic acid resulting in cysteic acid (sulphonate active acid radicals) which react with the active basic radical of the Alcian Blue stain and give the blue positive colour.

According to Bancroft and Gamble (2008), the neurosendocrine cells (NECs) achieved the production of specific peptides by coordinated gene expressions. The chromogranin A (CGA) was a member of family glycoprotein associated with the matrix of neurosecretory granules (Lassman et al., 1986) which may regulate peptide secretion (Wand et al., 1991). Histologically, CGA was an immunohistochemical marker identifies NECs containing numerous NSGs (Bancroft and Gamble, 2008). Consequently, the two nuclei of the hypothalamus subjected to Anti-CGA antibody using PAP technique. It reacted with an epitope on the Cterminal half of the CGA molecule and gave positive reaction appeared as brown coloured immune reactivecytoplasmic granules. These results discussed by Huttner et al. (1991) and Taupenot et al. (2003) who explained that the NECs produce a variety of bioactive peptides and amines stored in large densecore vesicles and in small neurotransmitter synapticlike vesicles. Some proteins were associated with these vesicles as granins (chromogranin and secretogranin) and synaptophysin which have been utilized as specific biomarkers of NECs.

According to Schmechel et al. (1978), the Neuron Specific Enolase was the enolaseisoenzyme found in NECs. Its presence was independent on the number of NSGs and its IHC identification was of some value in establishing the neuroendocrine phenotype in poorly granulated cells (Bancroft and Gamble, 2008), so that specimens in our study were treated with Anti-NSE antibody using PAP technique and showed strong immunoreactive cytoplasmic granules with dark brown colour which appeared small and filled the 
whole cytoplasm. The same positive reaction observed in the NECs of the pancreas, pineal gland, thyroid gland, pituitary gland and adrenal medulla of the rat, monkey and human (Schmechel et al., 1978). Murray et al. (1993) recorded that strong positive reaction indicate that these tissues expressed different isozymes of enolase either the $\alpha \alpha$ or $\beta \beta$ isozymes of enolase.

\section{REFERENCES}

Adams, C.W.M. and Sloper, J.C. (1955): Technique for demonstrating neurosecretory material in human hypothalamus. Lancet, 26, 651-652.

Adams, C.W.M. and Sloper, J.C. (1956): The hypothalamic elaboration of Posterior pituitary principles in man, the rat and dog. Histochemical evidence derived from a performic acid-alcian bluereaction for cystine. J. Endocr., 13, 221-222 .

Ambach, G. and Palkovits, M. (1979): The blood supply of the hypothalamus in the rat. In anatomy of the hypothalamus. Vol. 1, ed. Morgane P.J. and Panksepp J., 263-377. New York: Marcell, Dekker.

Bancroft, G.D. and Stevens, A. (1996): Theory and practice of histological techniques. $4^{\text {th }}$ Ed., Churchill-Livingstone, Edinburgh, London, Melborne, New York.

Bancroft, J. and Gamble, A. (2008): Theory and practice of histological techniques. $6^{\text {th }}$ Ed. Churchill-Livingstone, Edinburgh, London, Melbourne, New York.

Bargmann, W. (1949): Sober die neurosekretorische verknupfung von hypothalamus und neurohypophyse. Z. zellforsch. 34, 610-634. cited by Sloper (1989).

Barry, I. (1975): Essai de classification, entechnique de Golgi, des diverses categories de neurones de noyauparaventriculaire chez la souris. C.R. Seances Soc. BioL., 169: 978-980.

Bazhanova, E.D.; Grinevich, V.V. and Danilova, O.A. (1998): Neuroscience and Behavioral Physiology., 28(6): 26-29.

Bisset, G.W.; Clark, Barbara, J. and Haldar, Jaya (1970): Blood levels of oxytocin and vasopressin during suckling in the rabbit and the problem of their independent release. $\mathrm{J}$. Physiol. 206, 711-722.

Bõzse, Z.S. and Houdebine, L.M. (2006): Application of rabbits in biomedical research: A Review World Rabbit Sci., 14, 1-14.

Cetin, Y. (1992): Chromogranin A immunoreactivity and Grimelius' argyrophilia. Anat. Embryol. 185(3): 207-215.

Cotea, C.; Oprean, O.Z.; Boişteanu, P.; Solcan, Carmen, and Cotea, I. (2007): The nuclei of the hypothalamus in cow. Cercetări Agronomiceîn Moldova 4(132), 71-79.
De la Portilla, F.; López-Alonso, M.; Borrero, J.J.; Diaz-Pvon, J.; Gollonet, J.L.; Palacios, C.; Vazquez-Monchul, J. and Sánchez-Gil, J.M. (2011): The rabbit as an animal model for proctology research: anatomical and histological description. J. Investig. surg., 24(3): 134-137.

Duan, L.; Yuan, H.; Su, C.; Liu, Y. and Rao, Z. (2004): Ultrastructure of junction areas between neurons and astrocytes in rat supraoptic nuclei, World J. Gastroenterol., 10(1): 117-121.

Felten, D.L. and Cashner, K.A. (1979): Cytoarchitecture of the supraoptic nucleus: A Golgi study. Neuroendocrinol., 29, 221-230.

Flament-Durand, D. and Dustin, E. (1972): Studies on the transport of secretory granules in the magnocellular hypothalamic neurons. $\mathrm{Z}$. Zellforsch. Mikrosk. Anat., 130(4), 440-454.

Fliers, E.; Swaab, D.F.; Pool, C.W. and Verwer R.W.H. (1985): The vasopressin and oxytocin neurons in the human supraoptic and paraventricular nucleus: changes with aging and in senile dementia. Brain Res. 342: 45-53.

Freund-Mercier, M.J.; Stoeckel, M.E. and Klein, M.J. (1994): Oxytocin receptors on oxytocin neurones: histoautoradiographic detection in the lactating rat. J. Physiol., 480(1): 155-161.

Gomori, G. (1941): Observations with different stains on human islet of Langerhans. Amer. J. Pathol. 17: 395-406.

Graur, D.; Duret, L. and Gouy, M. (1996): Phylogenetic position of the order Lagomorpha (rabbits, hares and allies). Nature, 379, 333-335.

Gregory, W.A.; Tweedle, C.D. and Hatton, G.I. (1980): Ultrastructure of neurons in the paraventricular nucleus of normal dehydrated and rehydrated rats. Brain Research Bulletin, 5(3), 301-306.

Grimelius, L. (1968): A silver nitrate stain for $\alpha 2$ cells in human pancreatic islets. Acta Soc. Med. upsalien., 73: 243-270.

Harris, H.F. (1900): A new method of ripening haematoxyline. (Cited by Bancroft and Gamble, 2008).

Hayat, M.A. (1986): Basic techniques for transmission electron microscopy, Academic Press, Jovnovich Publishers. Inc. New York, Harcourt Brace.

Huttner, W.B.; Gerdes, H.H. and Rosa, P. (1991): The granin (chromogranin/ secretogranin) family. Trends Biochem. Sci. 16, 27-30.

Hyуррӓ, M. (1969): Differentiation of the hypothalamic nuclei during ontogenetic development in the rat. Zeits Für Anat Und Entwick., 129(1): 41-52.

Hyуррӓ, M. (1969): Differentiation of the hypothalamic nuclei during ontogenetic 
development in the rat. Zeits Für Anat Und Entwick., 129(1): 41-52.

Kalimo, J. (1975): Ultrastructural studies on the hypothalamic neurosecretory neurons of the rat. Cell Tiss. Res., 163, 151-168.

Lassman, H.; Hagn, C.; Fusher-Colbrie, R. and Winkler, H. (1986): Presence of CGA, B and $\mathrm{C}$ in bovine endocardium and nervous tissue; Acomparative immunohistochemical study; Histochem. J., 18, 380-386.

Leng, G.; Brown, C.H. and Russellin, J.A. (1999): Physiological pathways regulating the activity of magnocellular neurosecretory cells. Progress in Neurobiology, 57(6), 625-655.

Leontovich, T. (1970): The neurons of the magnocellular neurosecretory system of the dog's hypothalamus. A Golgi study. J. Him. orach., 11, 499-517.

Leveque, T.F. (1983): Changes in the neurosecretory cells of the rat hypothalamus following ingestion of sodium chloride. Anat. Rec., 117(4): 741-757.

Lundqvist, M.; Amberg, H.; Candell, J.; Malmgren, M.; Wilander, E.; Grimelius, L. and Oberg, K. (1990): Silver stains for identification of neuroendocrine cells: A study of the chemical background. Histochem. J.,22: 615-623.

Machfn-Santamaria, C. (1978): Ultrastructure of the hypothalamic neurosecretory nuclei of the dormouse (Eliomysquercinus L.) in the awakening and. J. Anat., 127, 239-249.

Murray, G.I.; Duncan, M.E.; Melvin, W.T. and Fothergill, J.E. (1993):Immunohistochemistry of neuron specific enolase with subunit specific antipeptide monoclonal antibodies. J. Clin. Pathol., 46: 993-996.

Pearse, A.G.E. (1977): The diffuse neuroendocrine system and the APUD concept: related endocrine peptides in brain, intestine, pituitary, placenta and anuran cutaneous glands. Med. Biol., 55, 115-125.

Rao, S.S.; Sarojini, R. and Jayalakshmi, K. (1988): Histomorphology and histochemistry of the neurosecretory system in penaeid prawn, Metapenaeusaffinis. J. Adv. Zool., 9(2): 113122.

Reynolds, E.S. (1963): The use of lead citrate at high $\mathrm{pH}$ as an electron opaque stain in electron microscopy. J. Cell Biol., 17: 208-212.

Richardson, K.C.; Jarett, L. and Finak, E.M. (1960): Embedding in epoxy resins for ultra-thin sectioning in electron microscopy. Stain Technol., 35: 313-323.

Saphier, D. and Feldman, S. (1985): Electrophysiologic evidence for neural connections between the paraventricular nucleus and neurons of the supraoptic nucleus in the rat. Exp. Neurol., 89, 289-294.
Scharrer, B. (1967): The neurosecretory neuron in neuroendocrine regulatory mechanisms. Amer. Zool., 7(1), 161-169.

Scharrer, E. and Scharrer, B. (1954): Hormones produced by neurosecretory cells. Recent Progress, Hormone Res., 10, 183-240.

Schmechel, D.; Marangos, P.J. and Brigtman, M.W. (1978): Neuron specific enolase is a molecular marker for peripheral and central neuroendocrine cells. Nature, 276, 834-836.

Shek, J.W.; Wen, G.Y. and Wisniewski, H.M. (1986): Atlas of the rabbit brain and spinal cord. New York state office of mental retardation and developmental disabilities, Institute of basic research in developmental disabilities, Staten Island, N. Y., USA.

SHI, L.; FAN, Y. and XU, Z. (2012): Development of Oxytocin- and Vasopressin Network in the Supraoptic and Paraventricular Nuclei of Fetal Sheep. Physiol. Res. 61: 277-286.

Sloper, J.C. (1989): Hypothalamic neurosecretion in the dog and cat, with particular reference to the identification of neurosecretory material with posterior lobe hormone. J. Anat., 20(2): 301-316.

Sofroniew, M.V.; Weindl, A.; Schinko, I. and Wetzstein, R. (1979): The distribution of vasopressin oxytocin and neurophysin producing neurons in the guinea pig brain. Cell Tiss. Res., 196, 367-384.

Solcia, E.; Vassallo, G. and Capella, C. (1968): Selective staining of endocrine cells by basic dyes after acid hydrolysis. Stain Technol., 43, 257-263.

Stafford, L. and Lightman, B.Y. (1988): The neuroendocrine paraventricular hypothalamus: Receptors, signal transduction, mRNA and neurosecretion. J. Exp. Biol., 49, 31-49.

Swaab, D.F. and Fliers, E. (1985): A sexually dimorphic nucleus in the human brain. Science, 228, 1112-1114.

Taupenot, L.; Harper, K.L. and O'Connor, D.T. (2003): The chromogranin-secretogranin family. N. Engl. J. Med. 348, 1134-1149.

Wand, G.S.; Takiyyuddin, M.; O'Connor, D.T. and Levine, M.A. (1991): A proposed role for CGA as a glucocorticoid responsive autocrine inhibitor of proopiomelanocortin secretion. Endocrinol., 128, 1345-1351.

Watkins, W.B. (1975): Immunohistochemical demonstration of neurophysin in the hypothalamo-neurohypophysial system. Int. Rev. Cytol. 41: in press.

Zaborszky, L.; Hoemke, L.; Mohlberg, H.; Schleicher, A.; Amunts, K. and Zilles, K. (2008): Stereotaxic probabilistic maps of the magnocellular cell groups in human basal forebrain. NeuroImage, 42(3): 1127-1141. 
$\underline{\text { Assiut Vet. Med. J. Vol. } 61 \text { No. } 147 \text { October } 2015}$

\section{دراسات نسيجية ونسيجية كيميائية ومناعية على النواة الوطائية المجاورة للبطين والنواة الوطائية فوق البصرية من منطقة ما تحت المهاد فى الأرانب النيوزيلاندي البالغة النة النيانة}

شحاتة محمد محمد سليمان ، خالد محد مظهر ، تغريل محد نبيل ، اسامة كمال معوض ، راندا معد حسن

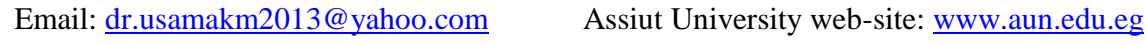

اجريت هذه الدر اسة علي المجموعة الأمامية من منطقة ما تحت المهاد في ذكور و انات الأرنب النيوزيلاندي البالغة. و واستهدفت هذه

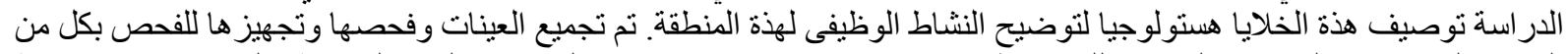

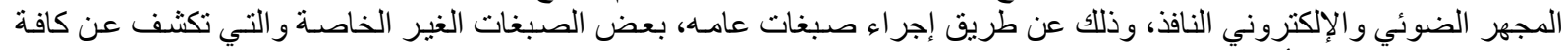

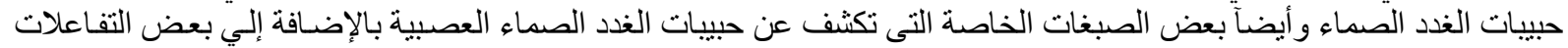

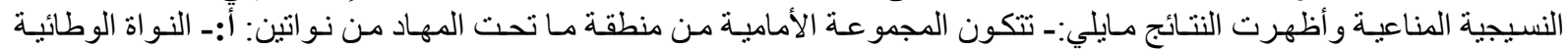

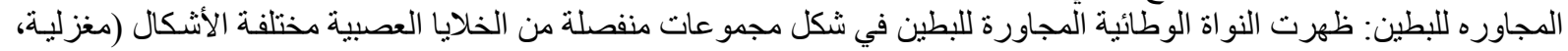

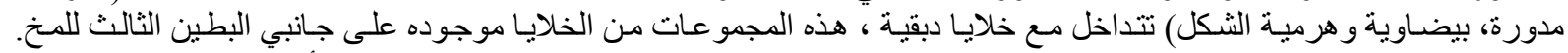

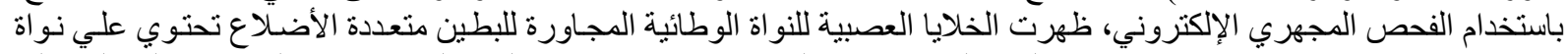

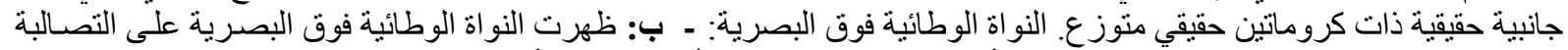

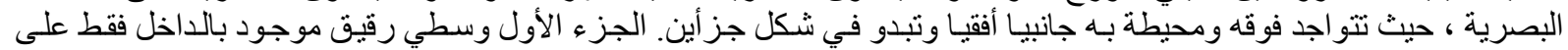

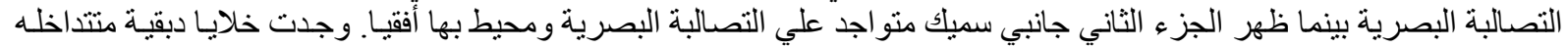

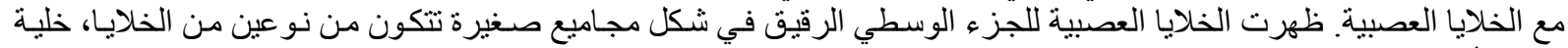

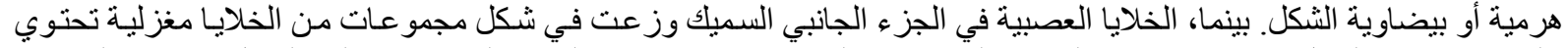

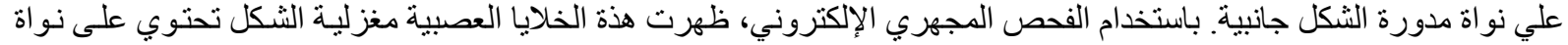

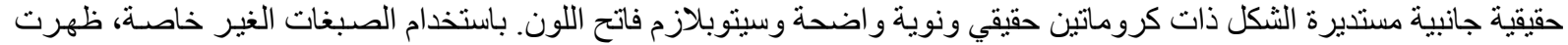

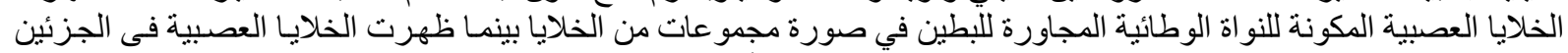

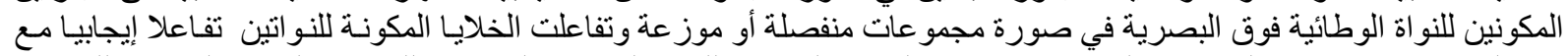

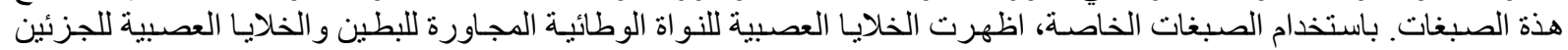

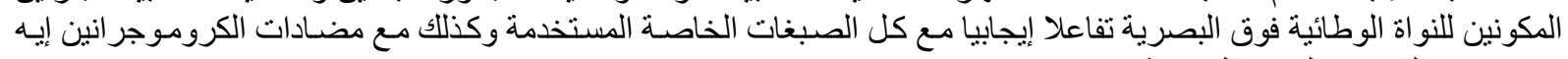
و الاينو لايز الخاص بالخلايا العصبية. 